\title{
Refractory Soft Tissue Sarcoma, Excluding Rhabdomyosarcoma
}

National Cancer Institute

\section{Source}

National Cancer Institute. Refractory Soft Tissue Sarcoma, Excluding

Rhabdomyosarcoma. NCI Thesaurus. Code C148459.

A finding indicating the presence of a sarcoma arising from the soft tissue, other than

rhabdomyosarcoma, that is resistant to treatment. 